\title{
PENERAPAN MODEL WATERFALL PADA SISTEM INFORMASI ADMINISTRASI PENDAFTARAN SEKOLAH MENGEMUDI BERBASIS WEB
}

\author{
Rahmawati $^{1}$, Lis Saumi Ramdhani ${ }^{2}$, Erika Mutiara ${ }^{3}$, Rizal Amegia Saputra ${ }^{4}$ \\ 1,2,3,4 Universitas Bina Sarana Informatika \\ Jl. Keramat Raya No. 18 Ringroad Barat, Cengkareng, Jakarta Barat \\ rahmawati@bsi.ac.id, lis.lud@bsi.ac.id, erika.emb@bsi.ac.id, rizal.rga@bsi.ac.id
}

\begin{abstract}
ABSTRAK
Lembaga Kursus Mobil Soedirman merupakan sebuah lembaga kursus yang membuka jasa kursus mobil khusus nya bagi warga sukabumi. Lembaga kursus mobil tersebut juga memberikan pelatihan yang baik dengan harga yang cukup terjangkau. Dalam pelayanan pendaftaran sistem pendaftarannya masih tulis tangan sehingga harus menggunakan waktu yang cukup lama, Pencatatan data yang masih tulis tangan dan tidak tertata menyebabkan sulitnya melakukan pencarian data/berkas yang sudah diinput sebelumnya dan kemungkinan arsip atau dokumen yang disimpan rentan dari resiko kehilangan atau rusak, kemudian bisa menyebabkan terjadinya kesalahan dan kerusakan dalam mencatat laporan karena masih menggunakan buku. Adapun metode pengumpulan data yang digunakan adalah Observasi, Wawancara, Studi Pustaka. Untuk mengatasi permasalahan tersebut, diusulkan pembuatan sistem berbasis web sebagai alat bantu dalam pengolahan data dan dapat menunjang pertanggungjawaban dalam penyajian laporan yang efektif dan efisien serta mempermudah dalam menghasilkan informasi yang berkualitas seperti yang dibutuhkan. Perangkat lunak dan tools yang digunakan yaitu Sublime Text dengan bahasa pemrograman PHP serta basis data MySQL. Dengan adanya sistem ini, proses transaksi administrasi pihak lembaga dan calon siswa menjadi lebih terorganisir dengan baik dan dapat meningatkan kualitas pelayanan serta efektivitas kinerja pihak lembaga..
\end{abstract}

Keywords: Administrasi pendaftaran, Sekolah Mengemudi, Sistem Informasi

\begin{abstract}
The Soedirman Car Course Institute is a course institution that opens special car course services for sukabumi residents. The car course institute also provides good training at a fairly affordable price. In the registration service the registration system is still handwritten so it must use a considerable amount of time. handwrittenl and unregistered data recording makes it difficult to search data / files that have been inputted before and the possibility of archives or documents stored is vulnerable to the risk of loss or damage, then can cause the occurrence of errors and damage in recording reports because they are still using books. The data collection methods used Observation, Interview, Library Study. To overcome these problems, it is proposed to create a web-based system as a tool in processing data and can support accountability in the presentation of reports that are effective and efficient and make it easier to produce quality information as needed. The software and tools used are Sublime Text with the PHP programming language and MySQL database. With this system, the administrative transaction process of the institution and prospective students becomes better organized and can improve service quality and the effectiveness of the institution's performance.
\end{abstract}

Keywords: Registration administration, Driving School, Information System 


\section{Pendahuluan}

Perkembangan teknologi informasi dan komunikasi menyebabkan banyaknya perubahan yang terjadi, bukan hanya yang perseorangan tetapi juga perusahaan dituntut untuk bisa menyesuaikan diri dengan perkembangan teknologi yang ada. Perkembangan teknologi informasi ini pun dapat dimanfaatkan oleh lembaga kursus sebagai bentuk penyediaan informasi maupun proses transksi agar dapat mempermudah calon siswa yang akan mendaftar (Hidayat, 2017).

Lembaga kursus atau disebut juga Lembaga Kursus dan Pelatihan (LKP) merupakan suatu lembaga yang menyediakan jasa pelatihan kepada para siswanya misalnya bimbingan belajar, komputer, bahasa Inggris, mengemudi, menjahit, dan sebagainya (Hindrajid, Widodo, \& Nugroho, 2016).

Lembaga Kursus Mobil Soedirman merupakan salah satu lembaga yang menyediakan jasa kursus mengemudi di kota Sukabumi yang sudah berdiri cukup lama, dan juga menjadi jasa kursus terbaik di kota Sukabumi berdasarkan rating yang diberikan dari siswa yang sudah mengikuti kursus mengemudi. Lembaga Kursus Mobil Soedirman salah satu lembaga kursus mengemudi yang masih menggunakan sistem administrasi manual. Lembaga ini cukup maju, dengan banyaknya siswa yang belajar di lembaga tersebut. Walaupun merupakan salah satu lembaga kursus yang banyak diminati dan berdiri sudah cukup lama pada tahun 1997 tetapi proses administrasi masih menggunakan buku untuk mencatat pendaftaran, pembayaran, jadwal dan absensi yang di tulis oleh bagian administrasi sehingga menimbulkan beberapa kendala seperti proses pencatatan administrasi pendaftaran masih menggunakan buku, kesulitan dalam proses pencarian data, kesalahan dalam pencatatan dan adanya data yang hilang.

Dari beberapa kendala tersebut maka dibuatlah sistem informasi administrasi pendaftaran sekolah mengemudi berbasis web ini diharapkan dapat menajdi solusi yang tepat untuk dipilih sebagai alat pembaruan sistem yang bisa digunakan untuk pengelolaan secara akurat, cepat, akuntabel, transparan sampai terarsip secara digital, juga dengan adanya sistem yang sudah terkomputerisasi akan mempermudah dan mempercepat proses administrasi pendaftaran dan pencatatan laporan keuangan pada lembaga kursus mobil Soedirman tersebut, sehingga kesalahan yang terjadi kemungkinan kecil.

Menurut Frediryana \& Sukadi, 2012 Suatu sistem adalah suatu jaringan kerja dari prosedur-prosedur yang saling berhubungan, berkumpul bersama-sama untuk melakukan suatu kegiatan atau untuk menyelesaikan suatu sasaran tertentu.

Pengertian Informasi adalah data yang telah diproses ke dalam suatu bentuk yang mempunyai arti bagi si penerima dan mempunyai nilai nyata dan terasa bagi keputusan saat itu atau keputusan mendatang (Syukroni, 2017).

Sebagaimana yang dikemukakan Alter dalam Nurdiyanti (2018), Sistem informasi adalah kombinasi antara prosedur kerja, informasi, orang, dan teknologi informasi yang diorganisasikan untuk mencapai tujuan dalam sebuah organisasi. Maka dalam pelaksanaannya harus dibuat terencana dan sesuai prosedur untuk memastikan sistem informasi berjalan dengan lancar karena sistem informasi merupakan kombinasi dari people, hardware, software, jaringan komunikasi, sumber-sumber data, prosedur dan kebijakan yang terorganisasi dengan baik yang dapat menyimpan, mengadakan lagi, menyimpan, dan menyebarluaskan informasi dalam suatu organisasi (Nurdiyanti, 2018).

\section{Metode Penelitian}

\subsection{Teknik Pengumpulan Data}

Penulis menggunakan beberapa metode untuk mengumpulkan data dalam penelitian ini diantaranya:

\section{a. Obeservasi}

Dilakukan dengan mengumpulkan beberapa data mengenai administrasi pendaftaran di lembaga kursus mobil soedirman untuk melihat dan mengidentifikasi kebutuhan sistem yang akan dibuat.

\section{b. Wawancara}

Selain observasi, dilakukan juga wawancara langsung terhadap para pengurus lembaga kursus mobil soedirman agar mendapatkan informasi secara rinci mengenai objek yang sedang diteliti dan yang akan dikembangkan.

c. Studi Pustaka 
Penulis juga menggunakan metode studi kepustakaan dengan membaca, dan mengambil referensi buku-buku, jurnal, artikel ilmiah, juga dari berbagai macam website yang berhubungan dengan judul penelitian ini, metode studi pustaka juga bisa memperkuat pendapat penulis.

\subsection{Model Pengembangan Sistem}

Berikut beberapa tahan pengembangan sistem Waterfall pada penelitian ini:

1. Analisa Sistem

Analisa dilakukan terhadap perangkat lunak yang akan dibangun berdasarkan kebutuhan pengguna aplikasi.

\section{Desain}

Desain dilakukan terhadap perangkat lunak yang akan dirancang agar sistem dapat berjalan dengan baik sesuai dengan yang diinginkan.

3. Pembuatan kode program

Desain harus ditranslasikan kedalam program perangkat lunak. Hasil dari tahap ini adalah program komputer sesuai dengan desain yang telah dibuat pada tahap desain.

4. Pengujian

Pengujian fokus pada perangkat lunak secara dari segi lojik dan fungsional dan memastikan bahwa semua bagian sudah diuji. Hal ini dilakukan untuk meminimalisir kesalahan (error) dan memastikan keluaran yang dihasilkan sesuai dengan yang diinginkan.

5. Pendukung (support) atau pemeliharaan (maintenance)

Tahap pendukung atau pemeliharaan dapat mengulangi proses pengembangan mulai dari analisis spesifikasi untuk perubahan perangkat lunak yang sudah ada tapi tidak untuk membuat perangkat baru.

\section{Hasil dan Pembahasan}

Penerimaan siswa baru pada Lembaga Kursus Mobil Soedirman berbasis web ini dirancang dengan beberapa hak akses yaitu admin dan petugas. Admin atau petugas dapat melakukan pendaftaran siswa baru, sedangkan akun petugas hanya bisa dikelola oleh admin. Berikut ini spesifikasi kebutuhan dari sistem pendaftaran siswa baru pada Lembaga Kursus Mobil Soedirman:

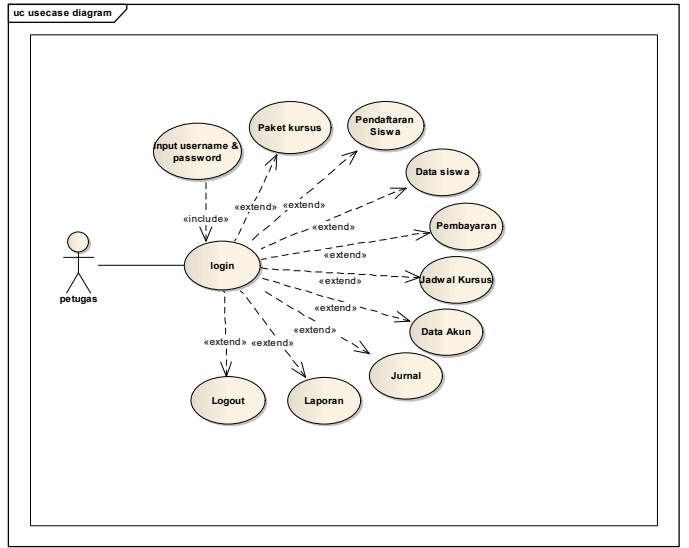

Gambar 1. Use Case Diagram Halaman Admin

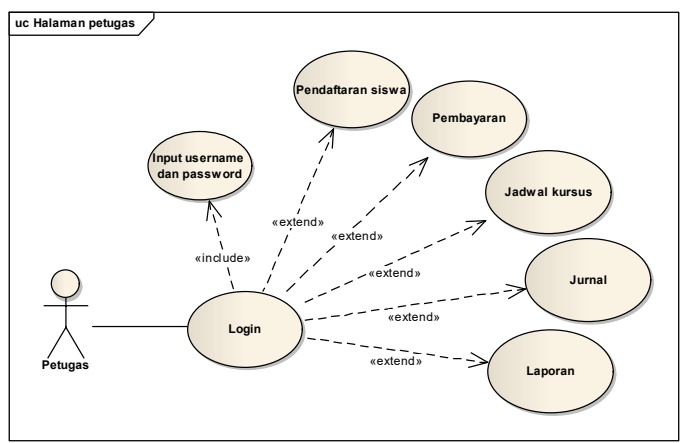

Gambar 2. Use Case Diagram Halaman Petugas

Proses pendaftaran siswa baru pada Lembaga Kursus Soedirman digambarkan dalam bentuk Activity Diagram sebagai berikut:

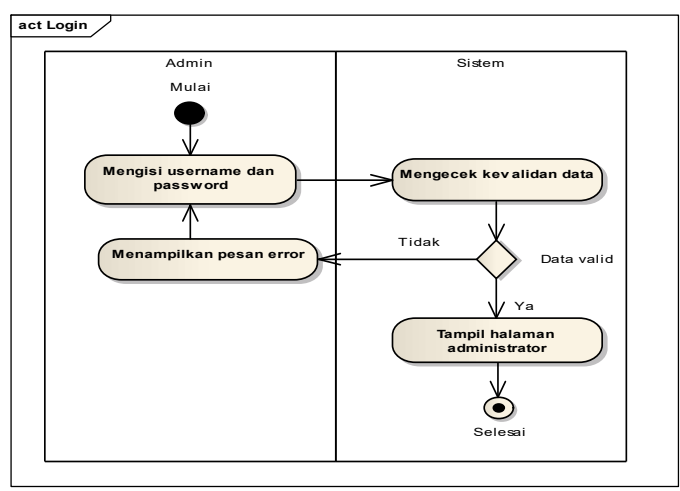

Gambar 3 Activity diagram login 


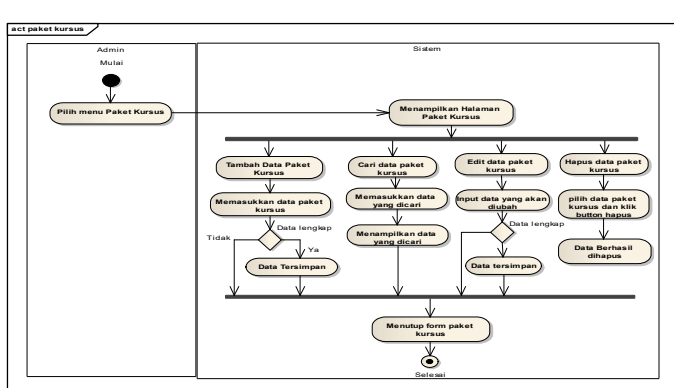

Gambar 4 Activity diagram paket kursus

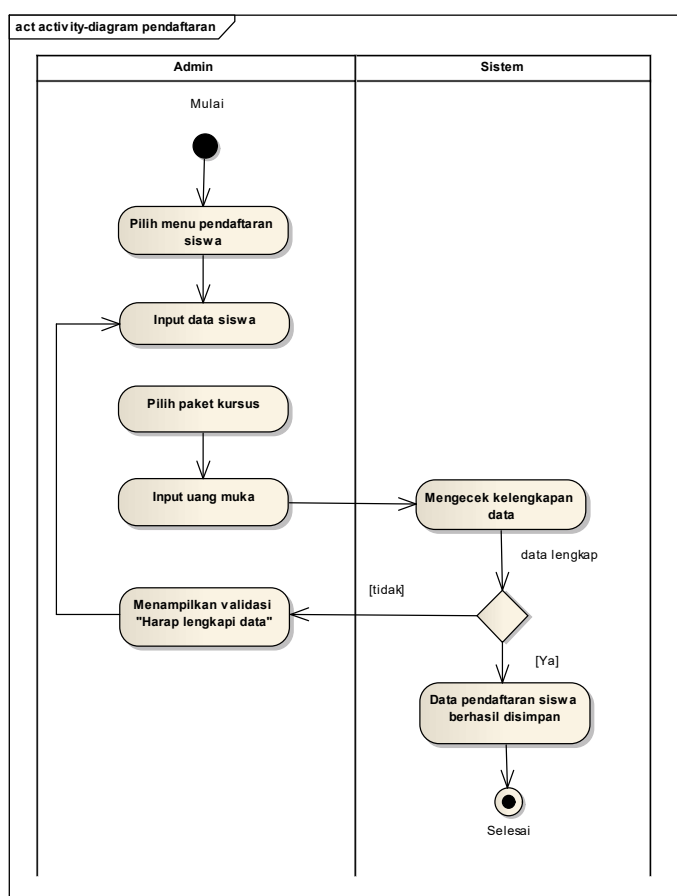

Gambar 5. Activity diagram pendaftaran siswa

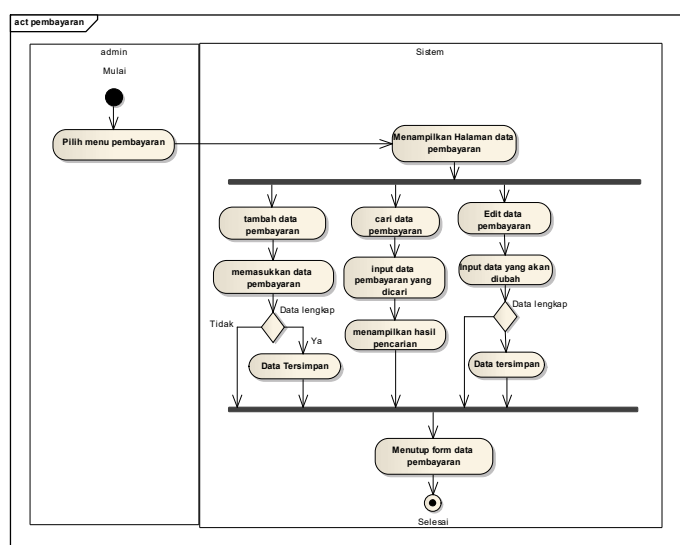

Gambar 6. Activity diagram pembayaran siswa

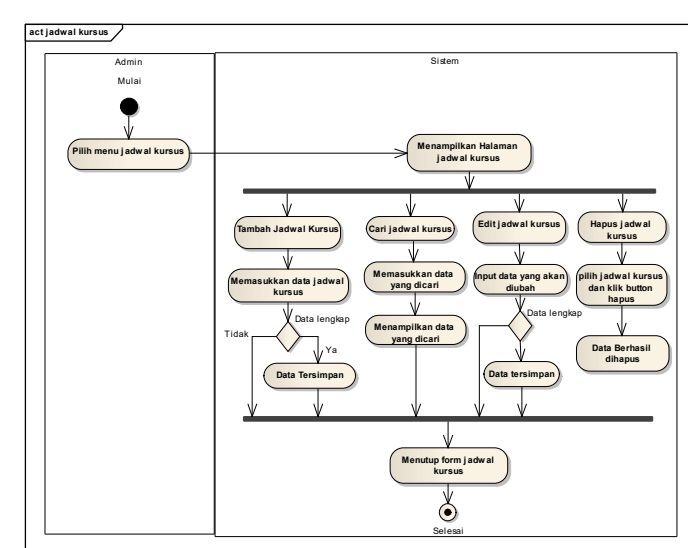

Gambar 7. Activity diagram jadwal kursus

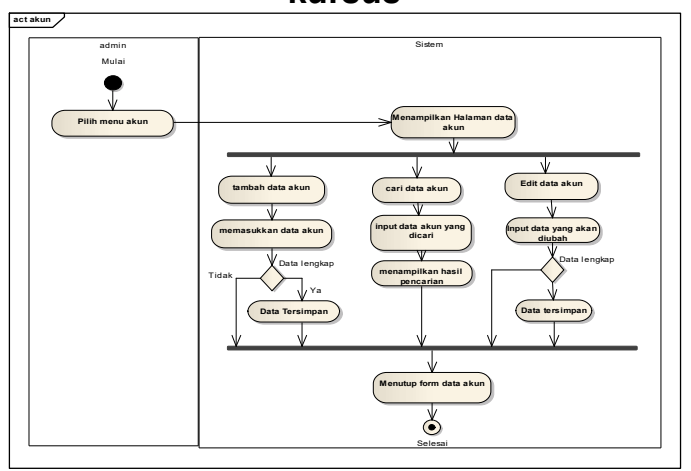

Gambar 8. Activity diagram akun

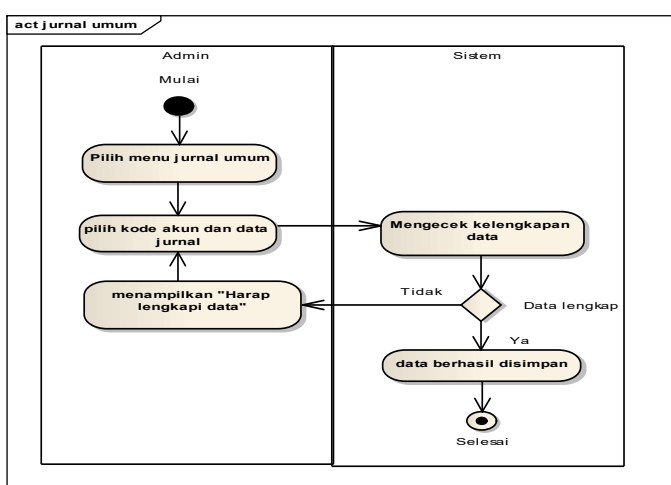

Gambar 9. Activity diagram jurnal umum

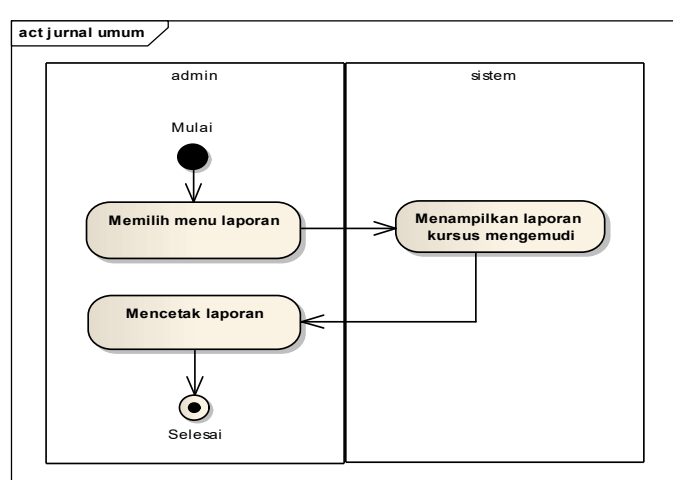

Gambar 10. Activity diagram laporan 
Proses desain sistem berupa penggambaran, perencanaan dan pembuatan dengan menyatukan beberapa elemen terpisah ke dalam satu kesatuan yang utuh untuk memperjelas bentuk dari sebuah sistem. Tahap desain dengan mengunakan ERD (Entity Relationship Diagram) dapat menjelaskan hubungan antar data dalam basis data (database) berdasarkan objek-objek dasar data yang mempunyai hubungan antar relasi dan sebagai salah satu alat bantu yang sangat handal di dunia pengembangan sistem

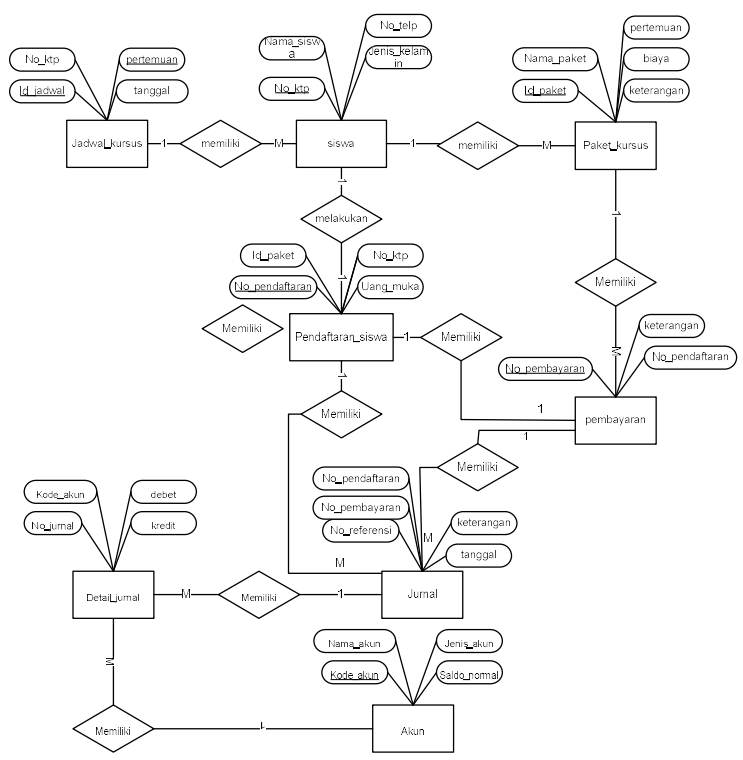

Gambar 11.Entity Relationship Diagram

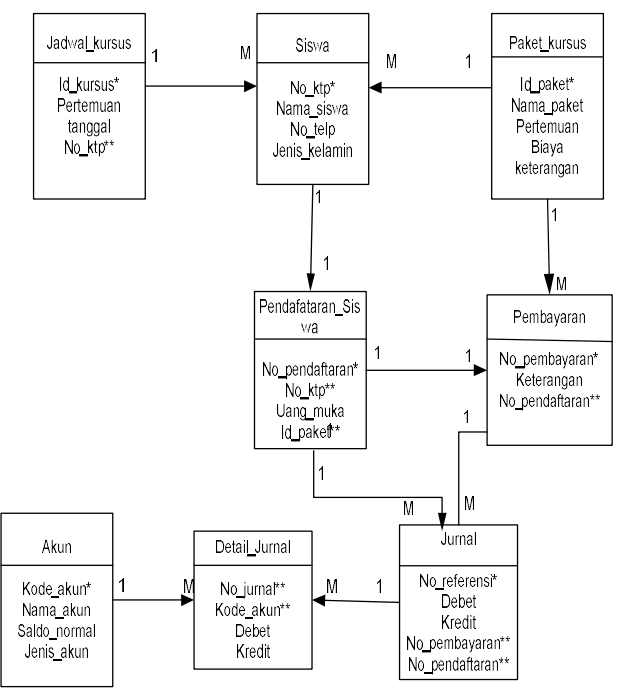

Gambar 12. Logical Record Diagram

Berikut adalah beberapa tampilan user interface untuk sistem informasi yang diusulkan:

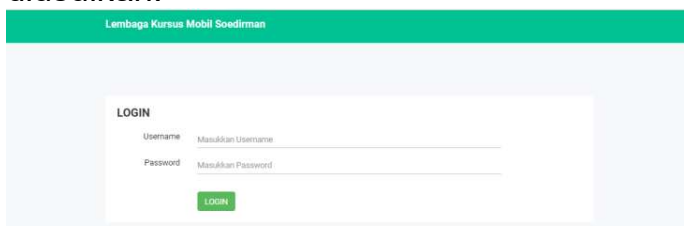

Gambar 13.User interface halaman login

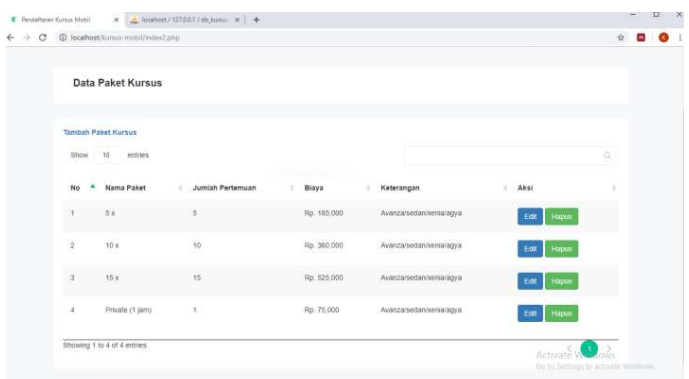

Gambar 14. User interface halaman paket kursus

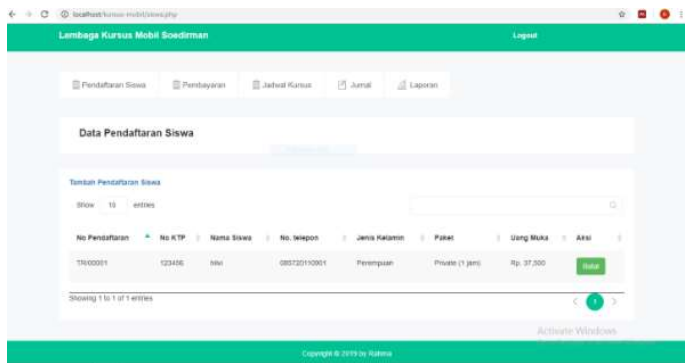

\section{Gambar 15.User interface halaman} pendaftaran siswa

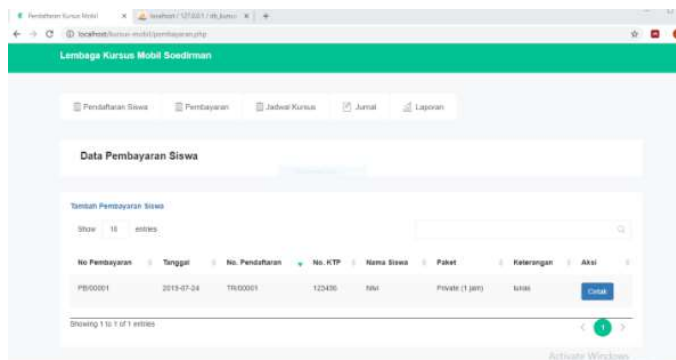

Gambar 16.User interface halaman pembayaran siswa

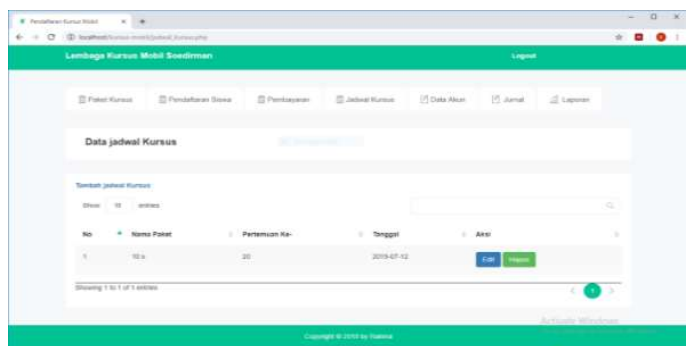

Gambar 17.User interface halaman jadwal kursus 


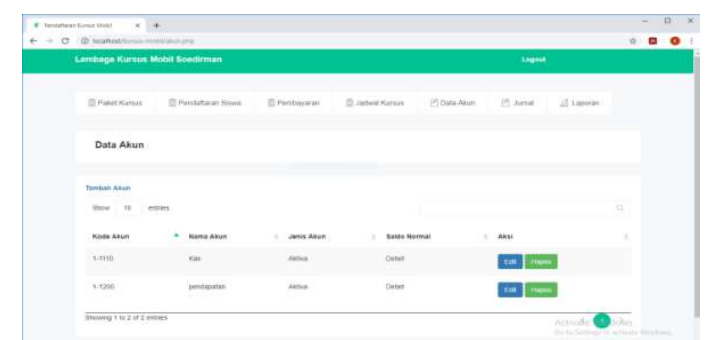

Gambar 18.User interface halaman data akun
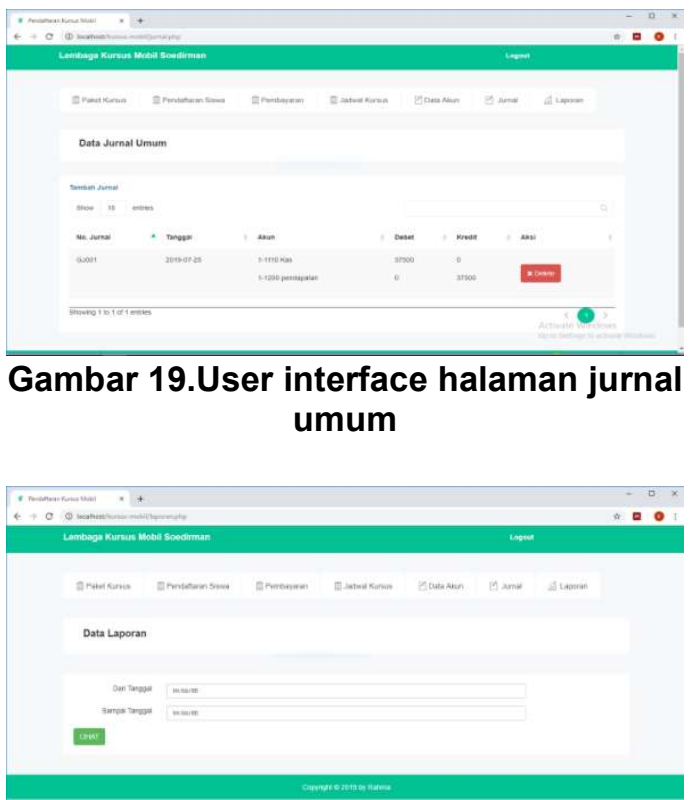

Gambar 20.User interface halaman laporan

\section{Kesimpulan}

Dari hasil penelitian dan pembahasan dalam Sistem Informasi Administrasi Pendaftaran Sekolah Mengemudi pada Lembaga Kursus Mobil Soedirman dapat ditarik kesimpulan-kesimpulan sebagai berikut :

1. Dalam sistem berjalan masih menggunakan sistem tulis tangan yang mengakibatkan terjadinya proses pendaftaran dan pembuatan laporan lebih memakan waktu, biaya dan tenaga karena kesulitan dalam mencari berkas yang telah masuk sebelumnya.

2. Sistem Informasi Administrasi Pendaftaran Sekolah Mengemudi berbasis Web dapat membantu bagian administrasi untuk mengelola dan mendapatkan informasi dengan cepat, tepat dan akurat, sehingga dapat meningkatkan kualitas pelayanan dan efektivitas kerja.
3. Dengan sistem informasi administrasi pendaftaran sekolah mengemudi berbasis Web, mempermudah dalam proses pembuatan dan percetakan laporan yang relevan menjadi lebih cepat dan keseluruhan data tersimpan dalam arsip digital (database) sehingga penyimpanan jauh lebih aman dan mengurangi resiko kehilangan dan kerusakan.

\section{Referensi}

Hidayat, R. (2017). Aplikasi Penjualan Jam Tangan Secara Online Studi Kasus: Toko JAMBORESHOP. Jurnal Teknik Komputer, III(2), 90-96.

Frediryana, A., \& Sukadi. (2012). Analisis Dan Perancangan Sistem Informasi Pendaftaran Mahasiswa Baru Pada Sekolah Tinggi Ilmu Tarbiyah Muhammadiyah Pacitan. Journal Speed - Sentra Penelitian Engineering Dan Edukasi, 4(1), 6372

Hindrajid, B., Widodo, A. A., \& Nugroho, A. P. (2016). Enterprise Sistem Administrasi Untuk Lembaga Kursus dan Pelatihan Studi Kasus di LKP Inka Group Pasuruan. JIMP Jurmal Informatika Merdeka Pasuruan, 2(1), 81-110.

Syukroni, M. F. (2017). Rancang Bangun Knowledge Management Sistem Berbasis Web Pada Madrasah Mualimin Al-Islamiyah Uteran Geger Madiun. 7-35.

Nurdiyanti, Y. (2018, January 5). PEMBAYARAN SPP DENGAN SYSTEM INFORMASI MANAJEMEN SEKOLAH: STUDI PADA MADRASYAH ALIYAH YPP BABAKAN JAMANIS. Journal Of Management Review, Volume 2 Number 1 (ISSN-P: 2580-4138 / ISSN-E: 2579-812X), 183-189. 